\title{
Expected Net Present Value of Pure and Mixed Sexed Semen Artificial Insemination Strategies in Dairy Heifers
}

\author{
N. J. Olynk ${ }^{1}$ and C. A. Wolf \\ Department of Agricultural Economics, Michigan State University, East Lansing 48824
}

\begin{abstract}
Sexed semen has been a long-anticipated tool for dairy farmers to obtain more heifer calves, but challenges exist for integrating sexed semen into commercial dairy farm reproduction programs. The decreased conception rates (CR) experienced with sexed semen make virgin heifers better suited for insemination with sexed semen than lactating dairy cows. This research sought to identify when various sexed semen breeding strategies provided higher expected net present value (NPV) than conventional artificial insemination (AI) breeding schemes, indicating which breeding scheme is advisable under various scenarios. Budgets were developed to calculate the expected NPV of various AI breeding strategies incorporating conventional (nonsexed) and sexed semen. In the base budgets, heifer and bull calf values were held constant at $\$ 500$ and $\$ 110$, respectively. The percentage of heifers expected to be born after breeding with conventional and sexed semen used was 49.2 and $90 \%$, respectively. Breeding costs per AI were held constant at $\$ 15.00$ per AI for conventional semen and $\$ 45.00$ per AI for sexed semen of approximately the same genetic value. Conventional semen CR of 58 and $65 \%$ were used, and an AI submission rate was set at $100 \%$. Breeding strategies with sexed semen were assessed for breakeven heifer calf values and sexed semen costs to obtain a NPV equal to that achieved with conventional semen. Breakeven heifer calf values for pure sexed semen strategies with a constant 58 and $65 \%$ base CR in which sexed semen achieved 53\% of the base CR are $\$ 732.11$ and $\$ 664.26$, respectively. Breakeven sexed semen costs per AI of $\$ 17.16$ and $\$ 22.39$, compared with $\$ 45.00$ per AI, were obtained to obtain a NPV equal to that obtained with pure conventional semen for base CR of 58 and 65\%, respectively. The strategy employing purely sexed semen, with base CR of both 58 and $65 \%$, yielded a lower NPV than purely conventional semen in all but the
\end{abstract}

Received July 21, 2006.

Accepted January 17, 2007.

${ }^{1}$ Corresponding author: olynknic@msu.edu best-case scenario in which sexed semen provides $90 \%$ of the CR of conventional semen. Other potential advantages of sexed semen that were not quantified in the scenarios include biosecurity-related concerns, decreased dystocia due to increased numbers of heifer calves, and implications for internal herd growth.

Key words: heifer reproduction, artificial insemination, budget, sexed semen

\section{INTRODUCTION}

Obtaining more offspring of a given sex via the use of sexed semen has been long anticipated by livestock industries for which sex is an economically important trait. Dairy farmers and the dairy industry alike have long awaited the technology capable of producing greater proportions of heifer calves, whereas other industries such as beef producers may desire higher proportions of bull calves. Dairy farmer interest in sexed semen is caused by a desire for herd expansion, internal herd growth, genetic progress, and increased biosecurity (Weigel, 2004). Breeding greater numbers of replacement animals for herd expansion or sale and the potential for more efficient terminal crossbreeding schemes are appealing to commercial dairy farms (Hohenboken, 1999). The decision to use sexed semen should, however, be based on whether producers can economically justify the additional costs associated with the use of sexed semen to obtain heifer calves.

Although many methods for sexing of bovine semen have been considered, the proven method licensed to XY Inc. (Fort Collins, CO) for commercial development is the Beltsville sperm sexing technology or fluorescence-activated cell-sorting approach of Johnson et al. (1987a,b, 1999). This method uses the approximately $3.8 \%$ differential in DNA content between bovine Xchromosome-bearing sperm and Y-chromosome-bearing sperm to sort sperm according to sex (Johnson et al., 1987a). In this method, sperm are treated with the DNA-specific fluorescent dye Hoechst 33342 and then sorted through use of high-throughput flow cytometry. Procedures for sperm sorting are described in detail elsewhere (Johnson, 2000; Seidel and Garner, 2002). 
Key challenges with sexed semen are the large proportion of sperm that remain unsorted, damage incurred by the sperm during sorting, and slow sorting speed when measured against commercial standards. With only $25 \%$ of the sperm processed being ultimately sexed, there is a large proportion of sperm that is discarded in the sorting process or lost due to logistical constraints (Seidel and Garner, 2002). Field trials performed on heifers have also identified bull-to-bull differences in sex sorting of sperm. Bull-specific effects of lower fertility have been observed, indicating that sperm from some bulls tolerates the stress of sex sorting procedures better than the sperm from other bulls (Seidel and Schenk, 2002).

Routinely, accuracy of sexing of approximately $90 \%$ is achieved, although this can be altered by the technician with the recognition that speed is to some extent a function of accuracy (Seidel, 2003). Sorting speed can be faster when sorting at lower levels of accuracy than at higher levels and is affected by the characteristics of an individual ejaculate, including number of dead sperm and the species of animal (Seidel, 2003). Given the challenges associated with the speed of sex sorting semen, the number of sexed sperm per straw is usually a low dose of approximately two million sperm, which is considerably less than the approximately twenty million sperm contained in a straw of conventional semen for $\mathrm{AI}$ in cattle.

Unlike the adoption of other reproductive sexing technologies, such as sexing of embryos or the use of ultrasound to sex fetuses, sexed semen could conceivably replace conventional semen used in AI with a minimal adjustment of on-farm management. Through several field trials, researchers have established that AI breeding with sexed semen can be used in production units utilizing varying management practices (Seidel et al., 1999) and can be performed successfully by both professional inseminators and dairy producers (Seidel and Schenk, 2002).

Discussion of the use of sexed semen is often focused on the value of heifer calves vs. the value of bull calves and the specific breeding costs to obtain them. To fully evaluate the expected net present value (NPV) of various entire breeding schemes, all additional costs associated with use of sexed semen to increase proportions of heifer calves must be taken into consideration by dairy producers. Additional costs with sexed semen include a price premium paid for sexed semen over traditional semen, as well as costs associated with the decreased conception rate $(\mathbf{C R})$ and concomitant increased services per conception (SPC). The decision to incorporate sexed semen technology into an AI-based breeding program should be based on whether producers can economically justify the additional costs associ- ated with the use of the technology in their operations. The added value of sexed semen is not simply the total value of calves produced through sexed semen use. Instead, the added value of sexed semen is correctly calculated as the difference between the value of calves obtained with conventional semen and the value of calves obtained with sexed semen. Due to the higher CR seen in virgin heifers over lactating dairy cattle, sexed semen is currently recommended for use solely in virgin heifers (Heifer Quest, 2006).

This research estimated the expected NPV of various pure and mixed sexed semen AI breeding strategies in virgin heifers. This research identified if and when various sexed semen breeding strategies provided higher expected NPV than conventional AI breeding schemes, indicating which breeding scheme is advisable under various scenarios. Sensitivity analyses were used to evaluate the effects of key assumptions, such as CR achieved with sexed semen, heifer calf values, and sexed semen costs on the results. Economically, the NPV of sexed semen breeding schemes was heavily dependent on increased breeding-related costs and decreased CR compared with conventional semen.

\section{MATERIALS AND METHODS}

Budgets were developed in Excel (Microsoft, Seattle, WA). The base scenarios used in the budget development focused on virgin heifer reproductive performance due to the higher $\mathrm{CR}$ in heifers than in lactating cows (DeJarnette, 2005). The fertility of virgin heifers since AI has been practiced in the United States has remained relatively constant at an approximately $65 \%$ first AI CR, whereas the first AI CR for cows has fallen substantially from 60 to $40 \%$ (Nebel, 2002). The budgets account for differences in costs between sexed semen and conventional nonsexed semen, CR with both conventional and sexed semen, proportion of calves born of each sex with conventional and sexed semen, and values associated with the heifer and bull calves obtained. The results are applicable to the habitual management of heifer reproduction programs on commercial dairy farms rather than niche uses such as dairy cattle show strings.

Cost differences between conventional semen and sexed semen per AI are represented in the budget through the semen cost per AI. The premium paid for the sexing procedure is assumed to be $\$ 30$ per straw (DeJarnette, 2005). This premium implies that sexed semen, which would have been available for $\$ 15$ per straw if left nonsexed, was offered for sale at approximately $\$ 45$ per straw. Per AI costs were held constant at $\$ 15$ and $\$ 45$ per insemination for conventional and sexed semen, respectively. 
The AI submission rate was set at $100 \%$ to reveal how changes in CR due to sexed semen use affect the value of sex-sorted semen. A $100 \% \mathrm{AI}$ submission rate could also represent the use of a synchronization program in which the submission rate for AI can be expected to approach that level. Probabilities of obtaining heifer and bull calves with conventional semen from a virgin heifer were assumed to be $49.2 \%$ female and $50.8 \%$ male (Ryan and Boland, 1991). With sexed semen, the sex ratio was set at $90 \%$ female and $10 \%$ male, indicating $90 \%$ accuracy in sexing. Accuracy in sexing sperm of $90 \%$ has been routinely achieved via field trials (Seidel et al., 1999; Seidel and Schenk, 2002) and was assumed across all scenarios analyzed with the budget.

The base CR of $58 \%$ for AI with conventional semen and $31 \%$ for AI with sexed semen were mean CR from field trials obtained from Weigel (2004). Achieving 53\% (31 vs. $58 \%$ ) of the $\mathrm{CR}$ with conventional semen with sexed semen is within the expected range of 50 to $60 \%$ under marginal to average cattle management (Seidel, 2003). In addition, Seidel (2003) stated that in situations with excellent cattle management, fertility with low doses of sexed semen has been roughly 70 to $80 \%$ of normal doses of conventional semen. Field trials have resulted in pregnancy rates with sexed semen in the 55 to $75 \%$ of conventional semen range (Seidel and Schenk, 2002 ). With respect to the assumption of achieving $90 \%$ of the fertility of conventional semen with sexed semen, Seidel (2003) stated this rate of fertility would not apply to all cattle and has not been thoroughly documented in any population. The values obtained by assuming sexed semen has a CR of $90 \%$ of the conventional semen $\mathrm{CR}$ are, therefore, optimistic. To incorporate all of the above possibilities, values were generated from the budget to assess the value of an AI with sexed semen assuming that CR with sexed semen were 53,75 , and $90 \%$ of those achieved with conventional semen. All CR scenarios were evaluated assuming both when CR remained constant across AI services and when CR decreased as AI service number increased. When the conventional semen CR of $58 \%$ was used, the sexed semen CR were 31,44 , and $52 \%$. When the conventional semen CR of $65 \%$ was used, the sexed semen CR were 34,49 , and $59 \%$. In total, $12 \mathrm{CR}$ scenarios were evaluated using 4 different AI breeding strategies, two of which were pure continuous strategies and two of which were mixed strategies using combinations of sexed and conventional semen. The 4 breeding strategies are denoted as follows: $\mathrm{S} 1$ = a single AI with sexed semen, followed by conventional semen; $\mathrm{S} 2=2 \mathrm{AI}$ with sexed semen, followed by conventional semen; $\mathrm{CS}=$ pure, continuous sexed semen; and $\mathrm{CC}=$ pure, continuous conventional semen.
The SPC of every scenario were calculated to achieve a minimum cumulative $90 \%$ pregnancy rate. That is, the heifer was assumed to be bred multiple times until an expected cumulative $90 \%$ chance of a pregnancy occurred. Once a cumulative $90 \%$ pregnancy rate was achieved, the remaining probability that the heifer was not pregnant was multiplied by her discounted cull value. Cull values for virgin heifers were assumed equal to its expected weight according to age at the time of cull multiplied by $\$ 1.10$ per kilogram and discounted according to time of cull in reference to the month of its initial breeding. Holstein heifer recommended weight tables were used to obtain expected heifer weights by age (Looper and Bethard, 2000). Calculations were performed assuming the first AI occurred at 14 mo of age. Costs of maintaining a nonpregnant breeding-age heifer were assumed $\$ 1.75$ per day (Fischer, 2002). The value of the calf and cull along with all costs incurred were discounted monthly at an annual rate of 9\% (Wolf et al., 2002).

Base values for heifer and bull calves were $\$ 500$ and $\$ 110$, respectively (Dairylea Cooperative Incorporated and Dairy Farmers of America Northeast Council, 2006). Each month, the value of the "average calf" was calculated by weighting the value of a heifer calf by the probability of the heifer calf and adding this value to the value of the bull calf weighted by the probability of the bull calf. The value of the average calf was then multiplied by the CR for that month and discounted according to the AI number, along with the cost of insemination and feed and raising costs. Costs to maintain a nonpregnant breeding-age heifer were calculated by weighting the cost of $\$ 1.75$ per day for an assumed $30.4 \mathrm{~d}$ a month by the probability of not being pregnant after a given AI. In other words, maintenance of $\$ 53.20$ was charged for each month that the heifer remained nonpregnant after her first AI at 14 mo of age. Following the AI, which exceeded a cumulative $90 \%$ expected pregnancy rate, the cull value of the virgin heifer at that time was weighted by the probability that the heifer was still nonpregnant and discounted. For example, if the cumulative pregnancy rate after the fourth AI was $94 \%$, the cull value was weighted by $6 \%$ and then discounted back from a month after her last breeding (to allow pregnancy check) to the month of the first AI, which occurred in month zero. The NPV of the strategy was then calculated by summing the values of all months required to reach the minimum cumulative $90 \%$ pregnancy rate.

The SPC necessary to achieve a $90 \%$ cumulative pregnancy rate were calculated for all $12 \mathrm{CR}$ scenarios. For calculating SPC in which decreasing CR was assumed as AI number increased, the second, third, and fourth or later AI were assumed to be $75.00,73.21$, and $62.50 \%$ 
of the first AI, respectively, for AI with conventional and sexed semen, based on Rankin et al. (1992).

The formula used to calculate the NPV of each AI, for both the pure and mixed AI breeding strategies, was as follows, with $\mathrm{NPV}_{\mathrm{t}}$ used for all except the last period and $\mathrm{NPV}_{\mathrm{T}}$ used for the last period only:

$$
\begin{gathered}
\mathrm{NPV}_{\mathrm{t}}=\mathrm{r} \times\left[\mathrm{CR}_{\mathrm{t}} \times \mathrm{VAC}-\left(1-\mathrm{PR}_{\text {cum }}\right) \times \text { Feed }-\mathrm{IC}\right] \\
\text { for } \mathrm{t}=1, \ldots, \mathrm{T}-1, \text { and } \\
\mathrm{NPV}_{\mathrm{T}}=\mathrm{r} \times\left[\mathrm{CR}_{\mathrm{T}} \times \mathrm{VAC}-\left(1-\mathrm{PR}_{\text {cum }}\right) \times \text { Feed }-\mathrm{IC}\right. \\
\left.+\left(1-\mathrm{PR}_{\text {cum }}\right) \times \mathrm{VCULL}_{\mathrm{T}}\right],
\end{gathered}
$$

where $\mathrm{CR}_{\mathrm{t}}=$ current $\mathrm{AI} \mathrm{CR} ; \mathrm{r}=$ discount rate; $\mathrm{VAC}=$ value of average calf $=$ (probability heifer calf $\times$ value heifer calf $)+$ (probability bull calf $\times$ value bull calf); $\mathrm{PR}_{\text {cum }}=$ cumulative percentage pregnant, defined as sum of PR from 1 through the current AI, in time $t$ [e.g., $\mathrm{PR}_{\text {cum }, 3}=\mathrm{CR}_{1}+\left(1-\mathrm{CR}_{1}\right) \times \mathrm{CR}_{2}+\left(1-\mathrm{CR}_{1}\right) \times(1$ $\left.-\mathrm{CR}_{2}\right) \times \mathrm{CR}_{3}$; Feed $=$ monthly feed and raising costs for nonpregnant breeding-age heifer $=(\$ 1.75$ per day $\times 30.4 \mathrm{~d}$ per month $)=\$ 53.20 ; \mathrm{IC}=$ insemination cost; and $\mathrm{VCULL}_{\mathrm{T}}=$ value of the culled heifer $=($ expected weight of heifer by age at time of cull) $\times$ [cull price $(\$ / \mathrm{kg})]$.

The NPV of the strategy was the sum from period 1 through $\mathrm{T}$, the total number of AI required to reach at least a cumulative $90 \%$ pregnancy rate:

$$
\mathrm{NPV}=\sum_{t=1}^{T} N P V_{t} .
$$

Breakeven analyses for heifer price and sexed semen costs per AI were calculated holding all other variables constant. Breakeven analyses were also conducted for what the $\mathrm{CR}$ of sexed semen must be in relation to conventional semen in order for CS to achieve an expected NPV equal to the CC.

\section{RESULTS AND DISCUSSION}

\section{Expected NPV of Breeding Strategies}

The SPC necessary to achieve a $90 \%$ cumulative pregnancy rate were calculated for all $12 \mathrm{CR}$ scenarios. The SPC necessary to achieve a $90 \%$ cumulative pregnancy rate for $\mathrm{CC}$ ranged from 3 to $4 \mathrm{SPC}$, with an integer average of 4 . The SPC for CS strategy across all the scenarios analyzed ranged from 3 to 10 , with an integer average of 6 . The SPC necessary to achieve at least a 90\% cumulative pregnancy rate were calculated. On average, upon reaching the $90 \%$ cumulative pregnancy rate, the cumulative probability of pregnancy was $93 \%$ in the pure conventional semen scenarios and $92 \%$ in the pure sexed semen scenarios. The mixed strategies of S1 and S2 had a range of 3 to 6 for SPC for the 58\% conventional CR group and 3 to 5 SPC for the $65 \%$ conventional CR group.

The expected NPV for the 4 breeding strategies of S1, S2, CS, and CC were obtained using the budget and analyzed across $12 \mathrm{CR}$ scenarios. The NPV calculated for the 4 breeding strategies are presented in Table 1 , in which the NPV of the CC strategy is presented in the first column, and the difference from the CC strategy is presented for S1, S2, and CS.

The CC strategy had a higher NPV than the CS strategy for all cases except when sexed semen yielded $90 \%$ of the control CR with a $58 \%$ base CR steadily across all AI services. With a $65 \%$ base $\mathrm{CR}$, the pure conventional semen strategy yielded a higher NPV than the CS strategy for all cases except when sexed semen yielded a constant or decreasing $90 \%$ of the control CR across all AI. Given that the assumption of $90 \%$ of the conventional semen CR being achieved with sexed semen is likely optimistic, the results indicate that according to expected NPV, the pure strategy of CC yielded a greater NPV than the CS strategy in the scenarios analyzed.

With both the 58 and $65 \%$ base CR scenarios, the NPV of S1 was higher than S2 except when sexed semen yielded 75 or $90 \%$ of the control CR steadily across all AI. When the pure and mixed strategies using base CR of 58 and $65 \%$ were compared, it was found that S1 yielded a higher NPV than CC semen for all cases except when sexed semen yielded 53\% of the control CR. Overall, in assessing the CS strategy, it yielded the lowest NPV of all strategies except when sexed semen yielded $90 \%$ steadily of the control CR with a $58 \%$ control CR and when sexed semen yielded $90 \%$ of the control CR with a $65 \%$ control CR.

Breakeven analyses for heifer calf values are shown in Table 2, to achieve a positive NPV and a NPV equal to that achieved with CC. As the value of the heifer calf decreases, fewer scenarios utilizing sexed semen provide a positive NPV. For example, breakeven analysis for the value of the heifer calf was performed holding all other variables constant on the following described scenario. A 58\% conventional semen CR was assumed and held constant across all AI. Sexed semen was assumed to provide a CR of $75 \%$ of the CR of conventional semen constantly across all AI, which was equal to $44 \%$ in this scenario. In order for the CS strategy to achieve a positive expected NPV, the newborn heifer calf must be worth at least $\$ 226.13$. For the CS strategy to achieve a NPV equal to the CC strategy, the heifer calf must be worth at least $\$ 512.81$.

Table 3 presents the breakeven sexed semen costs per insemination to achieve a positive NPV and a NPV 
Table 1. Comparison of expected net present value of pure and mixed sexed semen AI breeding strategies ${ }^{1}$

\begin{tabular}{|c|c|c|c|c|c|}
\hline $\begin{array}{l}\text { Proportion of the } \\
\text { conception rate } \\
\text { of conventional } \\
\text { semen obtained } \\
\text { with sexed } \\
\text { semen }(\%)\end{array}$ & $\begin{array}{c}\text { Conventional } \\
\text { semen base } \\
\text { conception rate } \\
(\%)\end{array}$ & $\mathrm{CC}^{2}$ & $\begin{array}{l}\text { Difference in } \\
\text { S1 over } \mathrm{CC}^{3}\end{array}$ & $\begin{array}{l}\text { Difference in } \\
\text { S2 over } \mathrm{CC}^{4}\end{array}$ & $\begin{array}{l}\text { Difference in } \\
\text { CS over } \text { CC }^{5}\end{array}$ \\
\hline 53 & $\begin{array}{l}58 \text { constant } \\
58 \text { decreasing }\end{array}$ & $\begin{array}{l}\$ 230.80 \\
\$ 208.20\end{array}$ & $\begin{array}{l}-\$ 24.30 \\
-\$ 28.32\end{array}$ & $\begin{array}{l}-\$ 31.64 \\
-\$ 68.81\end{array}$ & $\begin{array}{l}-\$ 190.56 \\
-\$ 336.05\end{array}$ \\
\hline 75 & $\begin{array}{l}58 \text { constant } \\
58 \text { decreasing }\end{array}$ & $\begin{array}{l}\$ 230.80 \\
\$ 208.20\end{array}$ & $\begin{array}{r}\$ 31.33 \\
\$ 5.07\end{array}$ & $\begin{array}{l}\$ 12.43 \\
-\$ 1.06\end{array}$ & $\begin{array}{l}-\$ 10.31 \\
-\$ 95.32\end{array}$ \\
\hline 90 & $\begin{array}{l}58 \text { constant } \\
58 \text { decreasing }\end{array}$ & $\begin{array}{l}\$ 230.80 \\
\$ 208.20\end{array}$ & $\begin{array}{l}\$ 49.07 \\
\$ 48.33\end{array}$ & $\begin{array}{l}\$ 58.51 \\
\$ 23.01\end{array}$ & $\begin{array}{r}\$ 4.01 \\
-\$ 30.21\end{array}$ \\
\hline 53 & $\begin{array}{l}65 \text { constant } \\
65 \text { decreasing }\end{array}$ & $\begin{array}{l}\$ 234.20 \\
\$ 235.62\end{array}$ & $\begin{array}{r}\$ 4.93 \\
-\$ 45.87\end{array}$ & $\begin{array}{l}-\$ 25.81 \\
-\$ 60.17\end{array}$ & $\begin{array}{l}-\$ 133.16 \\
-\$ 297.73\end{array}$ \\
\hline 75 & $\begin{array}{l}65 \text { constant } \\
65 \text { decreasing }\end{array}$ & $\begin{array}{l}\$ 234.20 \\
\$ 235.62\end{array}$ & $\begin{array}{l}\$ 38.38 \\
\$ 13.93\end{array}$ & $\begin{array}{l}\$ 46.49 \\
\$ 11.48\end{array}$ & $\begin{array}{r}-\$ 4.67 \\
-\$ 64.05\end{array}$ \\
\hline 90 & $\begin{array}{l}65 \text { constant } \\
65 \text { decreasing }\end{array}$ & $\begin{array}{l}\$ 234.20 \\
\$ 235.62\end{array}$ & $\begin{array}{l}\$ 60.69 \\
\$ 37.88\end{array}$ & $\begin{array}{l}\$ 68.42 \\
\$ 35.68\end{array}$ & $\begin{array}{r}\$ 55.61 \\
\$ 0.87\end{array}$ \\
\hline
\end{tabular}

\footnotetext{
${ }^{1}$ All strategies evaluated until a cumulative $90 \%$ probability of pregnancy was achieved.

${ }^{2} \mathrm{CC}=$ pure conventional semen breeding strategy.

${ }^{3}$ Difference between mixed breeding strategy of $1 \mathrm{AI}$ with sexed semen followed by conventional semen (S1) over CC. A negative value indicates that S1 provided a lower expected net present value than CC.

${ }^{4}$ Difference between mixed breeding strategy of $2 \mathrm{AI}$ with sexed semen followed by conventional semen (S2) over CC. A negative value indicates that S2 provided a lower expected net present value than CC.

${ }^{5}$ Difference between pure sexed semen breeding strategy (CS) over CC. A negative value indicates that CS provided a lower expected net present value than CC.
}

equal to that achieved with CC for both base CR of 58 a control CR of $65 \%$ decreasing across services and and $65 \%$ using pure and mixed breeding strategies. It sexed semen providing $53 \%$ of the control CR under is important to note that in many cases, such as with CS, the maximum that could be paid per straw of sexed

Table 2. Breakeven heifer calf values for pure and mixed conventional and sexed semen AI strategies

\begin{tabular}{|c|c|c|c|c|c|c|c|}
\hline \multirow{2}{*}{$\begin{array}{l}\text { Proportion of the } \\
\text { conception rate } \\
\text { of conventional } \\
\text { semen obtained } \\
\text { with sexed } \\
\text { semen }(\%)\end{array}$} & \multirow{2}{*}{$\begin{array}{c}\text { Conventional } \\
\text { semen base } \\
\text { conception rate } \\
(\%)\end{array}$} & \multicolumn{3}{|c|}{ To achieve positive NPV ${ }^{1}$} & \multicolumn{3}{|c|}{ To achieve NPV equal to $\mathrm{CC}^{2}$} \\
\hline & & $\mathrm{S} 1^{3}$ & $\mathrm{~S} 2^{4}$ & $\mathrm{CS}^{5}$ & $\mathrm{~S} 1^{3}$ & $\mathrm{~S} 2^{4}$ & $\mathrm{CS}^{5}$ \\
\hline 53 & $\begin{array}{l}58 \text { constant } \\
58 \text { decreasing }\end{array}$ & $\begin{array}{l}\$ 127.81 \\
\$ 184.21\end{array}$ & $\begin{array}{l}\$ 196.89 \\
\$ 281.97\end{array}$ & $\begin{array}{l}\$ 450.82 \\
\$ 660.46\end{array}$ & $\begin{array}{l}\$ 534.82 \\
\$ 549.73\end{array}$ & $\begin{array}{l}\$ 548.16 \\
\$ 607.64\end{array}$ & $\begin{array}{l}\$ 732.11 \\
\$ 921.75\end{array}$ \\
\hline 75 & $\begin{array}{l}58 \text { constant } \\
58 \text { decreasing }\end{array}$ & $\begin{array}{r}\$ 77.11 \\
\$ 162.47\end{array}$ & $\begin{array}{l}\$ 172.34 \\
\$ 202.98\end{array}$ & $\begin{array}{l}\$ 226.13 \\
\$ 359.46\end{array}$ & $\begin{array}{l}\$ 449.46 \\
\$ 491.98\end{array}$ & $\begin{array}{l}\$ 483.25 \\
\$ 501.52\end{array}$ & $\begin{array}{l}\$ 512.81 \\
\$ 618.68\end{array}$ \\
\hline 90 & $\begin{array}{l}58 \text { constant } \\
58 \text { decreasing }\end{array}$ & $\begin{array}{r}\$ 75.87 \\
\$ 107.07\end{array}$ & $\begin{array}{l}\$ 117.01 \\
\$ 152.55\end{array}$ & $\begin{array}{l}\$ 223.94 \\
\$ 283.74\end{array}$ & $\begin{array}{l}\$ 425.63 \\
\$ 425.97\end{array}$ & $\begin{array}{l}\$ 422.55 \\
\$ 465.42\end{array}$ & $\begin{array}{l}\$ 495.29 \\
\$ 536.70\end{array}$ \\
\hline 53 & $\begin{array}{l}65 \text { constant } \\
65 \text { decreasing }\end{array}$ & $\begin{array}{r}\$ 92.73 \\
\$ 181.23\end{array}$ & $\begin{array}{l}\$ 197.37 \\
\$ 230.06\end{array}$ & $\begin{array}{l}\$ 375.36 \\
\$ 576.94\end{array}$ & $\begin{array}{l}\$ 491.60 \\
\$ 577.07\end{array}$ & $\begin{array}{l}\$ 537.49 \\
\$ 592.58\end{array}$ & $\begin{array}{l}\$ 664.26 \\
\$ 868.75\end{array}$ \\
\hline 75 & $\begin{array}{l}65 \text { constant } \\
65 \text { decreasing }\end{array}$ & $\begin{array}{r}\$ 85.90 \\
\$ 115.28\end{array}$ & $\begin{array}{l}\$ 123.70 \\
\$ 155.21\end{array}$ & $\begin{array}{l}\$ 224.27 \\
\$ 286.85\end{array}$ & $\begin{array}{l}\$ 441.69 \\
\$ 478.52\end{array}$ & $\begin{array}{l}\$ 437.67 \\
\$ 483.98\end{array}$ & $\begin{array}{l}\$ 505.61 \\
\$ 579.58\end{array}$ \\
\hline 90 & $\begin{array}{l}65 \text { constant } \\
65 \text { decreasing }\end{array}$ & $\begin{array}{r}\$ 82.11 \\
\$ 108.14\end{array}$ & $\begin{array}{l}\$ 121.14 \\
\$ 146.72\end{array}$ & $\begin{array}{l}\$ 152.54 \\
\$ 213.17\end{array}$ & $\begin{array}{l}\$ 413.99 \\
\$ 445.73\end{array}$ & $\begin{array}{l}\$ 414.34 \\
\$ 453.53\end{array}$ & $\begin{array}{l}\$ 433.33 \\
\$ 498.95\end{array}$ \\
\hline
\end{tabular}

\footnotetext{
${ }^{1}$ The minimum heifer calf value needed to achieve a positive net present value (NPV) under the specified scenario.

${ }^{2}$ The minimum heifer calf value needed to achieve a NPV equal to the NPV of pure conventional semen breeding strategy (CC) under the specified scenario.

${ }^{3}$ Mixed breeding strategy of 1 AI with sexed semen followed by conventional semen (S1).

${ }^{4}$ Mixed breeding strategy of $2 \mathrm{AI}$ with sexed semen followed by conventional semen (S2).

${ }^{5}$ Pure sexed semen breeding strategy (CS).
} 
Table 3. Breakeven costs per insemination of sexed semen for pure and mixed conventional and sexed semen AI strategies

\begin{tabular}{|c|c|c|c|c|c|c|c|}
\hline \multirow{2}{*}{$\begin{array}{l}\text { Proportion of the } \\
\text { conception rate } \\
\text { of conventional } \\
\text { semen obtained } \\
\text { with sexed } \\
\text { semen }(\%)\end{array}$} & \multirow{2}{*}{$\begin{array}{c}\text { Conventional } \\
\text { semen base } \\
\text { conception rate } \\
(\%)\end{array}$} & \multicolumn{3}{|c|}{ To achieve positive $\mathrm{NPV}^{1}$} & \multicolumn{3}{|c|}{ To achieve NPV equal to $\mathrm{CC}^{2}$} \\
\hline & & $\mathrm{S} 1^{3}$ & $\mathrm{~S} 2^{4}$ & $\mathrm{CS}^{5}$ & $\mathrm{~S} 1^{3}$ & $\mathrm{~S} 2^{4}$ & $\mathrm{CS}^{5}$ \\
\hline 53 & $\begin{array}{l}58 \text { constant } \\
58 \text { decreasing }\end{array}$ & $\begin{array}{l}\$ 251.48 \\
\$ 224.87\end{array}$ & $\begin{array}{l}\$ 144.95 \\
\$ 114.95\end{array}$ & $\begin{array}{l}\$ 50.88 \\
\$ 31.78\end{array}$ & $\begin{array}{l}\$ 20.69 \\
\$ 16.68\end{array}$ & $\begin{array}{l}\$ 29.12 \\
\$ 10.47\end{array}$ & $\begin{array}{l}\$ 17.16 \\
\$ 10.25\end{array}$ \\
\hline 75 & $\begin{array}{l}58 \text { constant } \\
58 \text { decreasing }\end{array}$ & $\begin{array}{l}\$ 307.12 \\
\$ 258.26\end{array}$ & $\begin{array}{l}\$ 167.06 \\
\$ 148.95\end{array}$ & $\begin{array}{r}\$ 100.74 \\
\$ 64.17\end{array}$ & $\begin{array}{l}\$ 76.33 \\
\$ 50.07\end{array}$ & $\begin{array}{l}\$ 51.24 \\
\$ 44.47\end{array}$ & $\begin{array}{l}\$ 42.39 \\
\$ 28.82\end{array}$ \\
\hline 90 & $\begin{array}{l}58 \text { constant } \\
58 \text { decreasing }\end{array}$ & $\begin{array}{l}\$ 324.86 \\
\$ 301.53\end{array}$ & $\begin{array}{l}\$ 190.19 \\
\$ 161.03\end{array}$ & $\begin{array}{r}\$ 104.36 \\
\$ 81.13\end{array}$ & $\begin{array}{l}\$ 94.07 \\
\$ 93.33\end{array}$ & $\begin{array}{l}\$ 74.36 \\
\$ 56.55\end{array}$ & $\begin{array}{l}\$ 46.01 \\
\$ 38.87\end{array}$ \\
\hline 53 & $\begin{array}{l}65 \text { constant } \\
65 \text { decreasing }\end{array}$ & $\begin{array}{l}\$ 184.12 \\
\$ 234.74\end{array}$ & $\begin{array}{l}\$ 149.58 \\
\$ 133.05\end{array}$ & $\begin{array}{l}\$ 62.16 \\
\$ 37.89\end{array}$ & $\begin{array}{l}\$ 49.93 \\
-\$ 0.87\end{array}$ & $\begin{array}{l}\$ 32.05 \\
\$ 14.80\end{array}$ & $\begin{array}{l}\$ 22.39 \\
\$ 10.92\end{array}$ \\
\hline 75 & $\begin{array}{l}65 \text { constant } \\
65 \text { decreasing }\end{array}$ & $\begin{array}{l}\$ 317.58 \\
\$ 294.55\end{array}$ & $\begin{array}{l}\$ 185.87 \\
\$ 169.01\end{array}$ & $\begin{array}{r}\$ 103.02 \\
\$ 79.83\end{array}$ & $\begin{array}{l}\$ 83.39 \\
\$ 58.94\end{array}$ & $\begin{array}{l}\$ 68.33 \\
\$ 50.76\end{array}$ & $\begin{array}{l}\$ 43.82 \\
\$ 32.00\end{array}$ \\
\hline 90 & $\begin{array}{l}65 \text { constant } \\
65 \text { decreasing }\end{array}$ & $\begin{array}{l}\$ 339.88 \\
\$ 318.49\end{array}$ & $\begin{array}{l}\$ 196.87 \\
\$ 181.15\end{array}$ & $\begin{array}{l}\$ 142.32 \\
\$ 104.78\end{array}$ & $\begin{array}{r}\$ 105.69 \\
\$ 82.88\end{array}$ & $\begin{array}{l}\$ 79.34 \\
\$ 62.91\end{array}$ & $\begin{array}{l}\$ 63.67 \\
\$ 45.22\end{array}$ \\
\hline
\end{tabular}

\footnotetext{
${ }^{1}$ The maximum that can be paid for an AI with sexed semen to achieve a positive net present value (NPV) under the specified scenario.

${ }^{2}$ The maximum that can be paid for an AI with sexed semen to achieve a NPV equal to the NPV of the pure conventional semen breeding strategy (CC) under the specified scenario.

${ }^{3}$ Mixed breeding strategy of 1 AI with sexed semen followed by conventional semen (S1).

${ }^{4}$ Mixed breeding strategy of $2 \mathrm{AI}$ with sexed semen followed by conventional semen (S2).

${ }^{5}$ Pure sexed semen breeding strategy (CS).
}

semen to achieve a NPV equal to that with CC is less than the cost of conventional semen at $-\$ 0.87$. Such a situation indicates that it is impossible to make the NPV using sexed semen equal to that with the CC strategy through altering the semen price alone.

Breakeven analysis was used to determine the CR of sexed semen compared with conventional semen necessary to achieve an expected NPV with CS equal to the CC base strategy. In order for the CS strategy, evaluated steadily across all AI services, to yield an expected NPV equal to that achieved with CC using a base CR or $58 \%$, sexed semen must achieve at least $86 \%$ of the $\mathrm{CR}$ of conventional semen. With a constant base conventional CR of $65 \%$, sexed semen must yield $80 \%$ of the conventional CR for the NPV of the CS strategy to equal that achieved with the CC strategy.

Other economic analyses performed on the use of sexed semen have highlighted similar challenges relating to sexed semen use, including increased breeding costs due to decreased CR and sexed semen costs per AI (Seidel, 2003; Weigel, 2004). Seidel (2003) assumed fertility of sexed semen at $90 \%$ of that achieved with conventional semen and stated that sexed semen would be even more costly when assuming that sexed semen yields lower percentages of the fertility of conventional semen. Similar conclusions to those found in this study were drawn by Seidel (2003) regarding the importance of the value of heifer calves and sexed semen costs per AI to yield a comparable expected NPV with sexed semen and conventional semen use. Weigel (2004) explored multiple scenarios involving sexed semen. In analyzing the scenario of utilizing the purely sexed semen strategy highlighted in this analysis, Weigel (2004) concluded that the purchase of sexed semen could be justified at $\$ 50$ per unit at any CR as low as $35 \%$ for all AI, although at a cost of $\$ 100$ per unit, this would be hard to justify at any CR under $45 \%$ for all AI.

\section{Other Considerations for Sexed Semen Use on Dairy Farms}

Costs associated with increased maintenance costs due to increased SPC have been included in the calculation of the NPV of the breeding strategies. Additional discounting of the lactation value or changes in lactation performance was not accounted for in the NPV of the breeding strategies.

In the budgets developed, the AI submission rates were held constant at $100 \%$. It is important to note that $\mathrm{AI}$ submission rates of less than $100 \%$ will lead to decreased pregnancy rates compared with those calculated in the above budgets. The resulting decreased pregnancy rates would cause increased SPC over those calculated, leading to increased costs associated with maintaining the nonpregnant heifer and increased AI costs. 
Dystocia-related costs may also influence the decision to utilize sexed semen. Dematawewa and Berger (1997) reported that the average cost of dystocia for first-parity calvings was $\$ 28.53$. Statistics reported by Heifer Quest (2006) stated that the probability of difficult birth is $10.9 \%$ for bull calves and $5.3 \%$ for heifer calves, indicating that as increased proportions of heifer calves are born, the incidence of dystocia decreases. Costs obtained from Dematawewa and Berger (1997) for firstparity dams by dystocia score were $\$ 0.00, \$ 39.45$, $\$ 78.99, \$ 134.75$, and $\$ 383.03$ for dystocia scores of 1 , $2,3,4$, and 5. Clearly, potential cost savings exist when increased proportions of heifer calves are born and the chances of difficult births or dystocia scores of 4 and 5 are lessened. Seidel (2003) stated that the use of sexed semen to produce female calves could reduce the dystocia costs in first-parity heifers by around $20 \%$.

Genetic gains associated with sexed semen have been long debated. Baker et al. (1990) cited that the main advantage in genetics of utilization of female-producing sperm is that it allows increases in selection intensity on the female, because replacement heifers are more readily available. Baker et al. (1990) stated that although controlling for the sex of offspring may not have large effects on the rate of genetic progress, the potential for large gains in efficiency of farming systems exist.

Synergies are currently being explored between sexed semen and other reproductive technologies for use on commercial dairy farms. For example, in vitro production (IVP) of embryos has been restricted by costs, inefficiencies, and decreased CR for use on commercial dairy farms (Wilson et al., 2005). Wilson et al. (2005) have contended that “... IVP and sperm sorting may have synergies that would allow these technologies to be combined effectively in modern breeding programs" (p. 776). Fewer sperm than conventional AI are required for IVP, which makes it well suited to the decreased sperm numbers in a dose of sexed semen. Wilson et al. (2005) concluded that although commercial use of either sexed semen or IVP in breeding systems is limited, capitalizing on the synergies and utilization of the technologies together could play an important role in commercial livestock breeding programs.

A widely recognized potential benefit of sexed semen use is biosecurity through internal herd production of heifers and internal herd growth. Costs associated with introduction of disease through bringing in outside cattle vary depending on the disease, overall cattle health, disease control measures used, and the biosecurity measures in place. Faust et al. (2001) interviewed managers of dairy farms and found that fewer than 50\% of those managers interviewed required health testing for incoming cattle, about $50 \%$ practiced quarantine of in- coming cattle, and almost $60 \%$ of those interviewed obtained cattle from places where health histories and genetics were hard to document. Therefore, room for improvement in biosecurity procedures for incoming cattle on dairy farms exists in many cases.

Potential for increased biosecurity through sexed semen for internal herd growth is often discussed in relation to expanding dairy herds. However, opportunities from improved biosecurity exist for both expanding and static herds, such as sale of calves or heifers, employing a custom heifer grower, or practicing more selective voluntary culling. Creative employment of facilities and outside heifer facilities could even allow for milking herd expansion without the immediate need for acquiring additional facilities.

Early adoption of new technologies on dairy farms depends on various factors such as the degree of risk aversion of the operator, the financial position of the farm, the availability of or access to information on the technology, and the level of risk associated with the technology. Uncertainty about performance of new technologies will arise both from the lack of performance history, as well as a lack of knowledge, which could be caused by asymmetric information. Looking beyond risk and uncertainty, some individuals have an affinity for implementing the newest and most advanced technologies.

Beyond analysis of expected NPV of breeding strategies synergies with other reproductive technologies, increased biosecurity, and increased opportunity for herd expansion offer incentives to pursue increased proportions of heifer. Further, revenue from sale of calves or older heifers or utilization of a custom heifer grower offers opportunities for capitalization on additional heifer numbers without herd or facility expansion.

\section{CONCLUSIONS}

The decision to adopt semen sexing technology into a commercial dairy operation depends on many factors, including CR with conventional semen, CR with sexed semen, and values of heifer and bull calves. The NPV of the CC strategy, which used purely conventional semen, was higher than the CS strategy, which used purely sexed semen, in all but the best case scenario in which sexed semen yielded $90 \%$ of the CR of conventional semen. In order for the CS strategy, evaluated steadily across all AI services to yield an expected NPV equal to that achieved with CC using a base CR or $58 \%$, sexed semen must yield at least $86 \%$ of the CR of conventional semen. When the heifer calf was worth $\$ 500$, the S1 strategy, a mixed strategy that used a single AI with sexed semen followed by AI with conventional semen, yielded a higher NPV than the CC strat- 
egy for the majority of the scenarios tested. Given that the scenario in which sexed semen yields $90 \%$ of the CR of conventional semen is currently unlikely, and that the majority of cases in which sexed semen yielded higher values than conventional semen occurred under the $90 \%$ of the conventional CR scenarios, there are limited remaining scenarios in which sexed semen can be recommended.

\section{REFERENCES}

Baker, R. L., P. Shannon, D. J. Garrick, H. T. Blair, and B. W. Wickham. 1990. The future impact of new opportunities in reproductive physiology and molecular biology on genetic improvement programmes. Proc. N. Z. Soc. Anim. Prod. 50:197-210.

Dairylea Cooperative Inc. and Dairy Farmers of America Northeast Council. 2006. Friday Facts Archives. http://www.dairylea.com/ News_and_Publications/FridayFacts/archive/archive.htm Accessed Jan. 6, 2006.

DeJarnette, M. 2005. Subject: Selections Dairy Newsletter. http:// www.selectsires.com/selections/2005_q1_page8-9.pdf Accessed Jan. 13, 2006.

Dematawewa, C. M., and P. J. Berger. 1997. Effect of dystocia on yield, fertility and cow losses and an economic evaluation of dystoica scores for Holsteins. J. Dairy Sci. 80:754-761.

Faust, M. A., M. L. Kinsel, and M. A. Kirkpatrick. 2001. Characterizing biosecurity, health, and culling during dairy herd expansions. J. Dairy Sci. 84:955-965.

Fischer, D. B. 2002. Is custom heifer raising for you? http://www.traill. uiuc.edu/dairynet/paperDisplay?ContentID=359 Accessed Apr. 10, 2006.

Heifer Quest. 2006. The benefits of utilizing sexed semen. http:// www.heiferquest.com Accessed Jan. 13, 2006.

Hohenboken, W. D. 1999. Applications of sexed semen in cattle production. Theriogenology 52:1421-1433.

Johnson, L. A. 2000. Sexing mammalian sperm for the production of offspring: The state-of-the-art. Anim. Reprod. Sci. 60-61:93-107.
Johnson, L. A., J. P. Flook, and M. V. Look. 1987a. Flow cytometry of $\mathrm{X}$ and $\mathrm{Y}$ chromosome-bearing sperm for DNA using an improved preparation method and staining with Hoechst 33342. Gamete Res. 17:203-212.

Johnson, L. A., J. P. Flook, M. V. Look, and D. Pinkel. 1987b. Flow sorting of $\mathrm{X}$ and $\mathrm{Y}$ chromosome-bearing spermatozoa into two populations. Gamete Res. 16:1-9.

Johnson, L. A., G. R. Welch, and W. Rens. 1999. The Beltsville sperm sexing technology: High speed sorting give improved sperm output for in vitro fertilization and AI. J. Anim. Sci. 77:213-220.

Looper, M., and G. Bethard. 2000. Management considerations in Holstein heifer development. Guide B-118. http://www.cahe. nmsu.edu/pubs/_b/B-118.html Accessed Apr. 8, 2006.

Nebel, R. L. 2002. Subject: What should your AI conception rate be? http://www.ext.vt.edu/news/periodicals/dairy/2002-05/ai conception.html Accessed Jan. 13, 2006.

Rankin, T. A., W. R. Smith, R. D. Shanks, and J. R. Lodge. 1992. Timing of insemination in dairy heifers. J. Dairy Sci. 75:28402845 .

Ryan, D. P., and M. P. Boland. 1991. Frequency of twin births among Holstein-Friesian cows in a warm dry climate. Theriogenology $36: 1-10$.

Seidel, G. E., Jr. 2003. Economics of selecting for sex: The most important genetic trait. Theriogenology 59:585-598.

Seidel, G. E., Jr., and D. L. Garner. 2002. Current status of sexing mammalian spermatozoa. Reproduction 124:733-743.

Seidel, G. E., Jr., and J. L. Schenk. 2002. Field trials with sexed, frozen bovine semen. Pages 64-69 in Proc. 19th Technol. Conf. Artif. Insemination Reprod. Natl. Assoc. Anim. Breeders, Columbia, MO.

Seidel, G. E., Jr., J. L. Schenk, L. A. Henrickhoff, S. P. Doyle, Z. Brink, R. D. Green, and D. G. Cran. 1999. Insemination of heifers with sexed sperm. Theriogenology 52:1407-1420.

Weigel, K. A. 2004. Exploring the impact of sexed semen in dairy production systems. J. Dairy Sci. 87(E. Suppl.):E120-E130.

Wilson, R. D., K. A. Weigel, P. M. Fricke, J. J. Rutledge, M. L. Leibfried-Rutledge, D. L. Matthews, and V. R. Schutzkus. 2005. In vitro production of Holstein embryos using sex-sorted sperm and oocytes from selected cull cows. J. Dairy Sci. 88:776-782.

Wolf, C., S. Hanson, E. Wittenberg, and S. Harsh. 2002. Discount rates for dairy farms. Michigan State Univ. Agric. Econ. staff paper 02-08. Michigan State Univ., East Lansing. 